\title{
Perancangan Blueprint Sistem Informasi Mekanisme Kinerja Bidang Penunjang Dosen Berdasarkan Tel-U POINT Di Fakultas Rekayasa Industri Universitas Telkom Menggunakan Waterfall Model
}

\author{
Pramesti Intan Meuthia, Litasari Widyastuti Suwarsono, Atya Nur Aisha \\ Program Studi S1 Teknik Industri, Fakultas Rekayasa Industri, Universitas Telkom, Bandung, Indonesia, Jl. Telekomunikasi Jl. Terusan \\ Buah Batu No.01, Sukapura, Kec. Dayeuhkolot, Kota Bandung, Jawa Barat 40257
}

\section{KEYWORDS}

Blueprint, Perguruan Tinggi, Proses Bisnis,
User Interface, Website.

\section{CORRESPONDENCE}

Phone: 087791345185

E-mail: pramesti51@gmail.com

\section{PENDAHULUAN}

Perguruan tinggi merupakan salah satu tempat untuk mengembangkan kompetensi, yang mana akan mempersiapkan peserta didik (sumber daya manusia) untuk menjadi anggota masyarakat yang memiliki kemampuan akademis dan profesional yang dapat menerapkan, mengembangkan dan menciptakan ilmu pengetahuan, teknologi dan kesenian [1]. Di Indonesia, perguruan tinggi dapat berupa akademik, politeknik, sekolah tinggi, institut atau universitas. Universitas menawarkan pendidikan akademik dan/atau vokasi dalam berbagai kelompok disiplin ilmu pengetahuan, teknologi dan/atau seni [2]. Dalam penerapannya universitas bergantung pada kinerja SDM yang menjadi anggota didalamnya untuk menciptakan generasi sumber daya manusia yang unggul. Dalam hal ini termasuk dosen sebagai sumber daya manusia utama di dalam perguruan tinggi. Universitas Telkom khususnya di Fakultas Rekayasa Industri, dosen merupakan penyokong utama dalam sumber daya manusia. Universitas Telkom memiliki tiga tipe dosen, yaitu Dosen Tetap, Dosen Profesional, dan Dosen Luar Biasa.

Di dalam perguruan tinggi, dosen mengemban tugas utama yang dikenal dengan Tri Dharma Perguruan Tinggi, yaitu kegiatan pendidikan dan pengajaran, penelitian dan pengembangan, serta pengabdian masyarakat. Di dalam Universitas Telkom untuk pengembanan tugas dosen terdapat suatu pegangan yang disebut dengan Tel-U Point. Berikut merupakan Gambaran dari Tel U Point mengenai beban kerja dosen.

\begin{abstract}
A B S T $\mathbf{R}$ A $\mathbf{C}$ T
Higher education is one of the places to develop competencies, which will prepare students versities, lecturers carry out the main task known as the Tri Dharma College, namely lkom University in activities, research and development, and community service, while bjective and there is injustice in the verification process, as well as collecting data related to

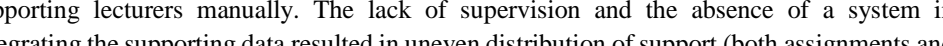
points obtained) and the absence of track records for lecturers. So that it requires a proposed business process design, blueprint document design, and the design of a user interface that is in gineering Faculty with interesting and accessible visualization anywhere. With the design of bsite-based information support mechanisms, it is expected that the control holders in process can be clearly illustrated, supporting data can be well integrated, and data filling d storage can be automated in the system.
\end{abstract}

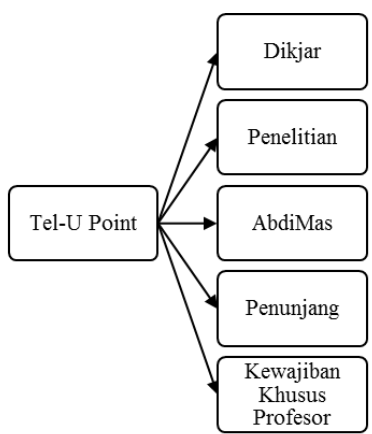

Gambar 1 Tel-U Point Beban Kerja Dosen Sumber: SK Sistem Kinerja Institusi No. KR. 108/SDM03/WR2.0.0/2014

Penelitian kali ini membahas mengenai mekanisme komponen kerja dosen di poin nomor empat yaitu bidang Penunjang. Penunjang adalah kegiatan yang dilakukan oleh dosen diluar dari Tridharma Perguruan Tinggi, seperti menjadi pimpinan pembinaan Unit Kegiatan Mahasiswa, pembimbing kelompok kompetisi, mengikuti pelatihan yang linier dengan disiplin ilmu, dan lain-lain. Berikut merupakan Persentase Data Beban Kerja Dosen Bidang Penunjang Eksisting. 
Persentase Data Beban Kerja Dosen Bidang Penunjang Eksisting



Gambar 2 Persentase Data Beban Kerja Dosen Bidang Penunjang Eksisting Sumber: Wakil Dekan II Fakultas Rekayasa Industri

Dalam hal pendokumentasian bidang penunjang juga terdapat beberapa kelemahan, yaitu:

- Untuk pengisian data penunjang masih dilakukan secara manual karena hanya berupa rubrik excel, dan

Di dalam rubrik excel tersebut terdapat pilihan seperti surat tugas "ada" atau "tidak ada" dan laporan "ada" atau "tidak ada”.

- Tidak ada fasilitas untuk menyimpan berkas penunjang karena tidak adanya sistem yang khusus mengatur dalam hal penunjang dosen.

Evidence fisik (hardcopy/softcopy) dikelola secara manual oleh SDM Fakultas sehingga tidak terotomatisasi didalam sistem.

Akibat dari permasalahan diatas, dapat menimbulkan dampak sebagai berikut:

- Subjektif,

Jika fakultas yang memiliki Kaur SDM "strict" dalam verifikasi laporan banyak yang tidak diakui penunjangnya, begitu pula sebaliknya jika Kaur SDM "flexible" dalam verifikasi laporan (contoh: surat tugas/SK pengangkatan ada, tetapi tidak ada laporan penugasan) tetap diakui penunjangnya.

- Adanya ketidak adilan dalam proses verifikasi dan pemberian poin SKS,

SDM Pusat menerapkan asas "percaya" terhadap Kaur SDM Fakultas terkait dengan verifikasi data laporan penunjang dosen, sehingga tidak ada pengawasan lebih dalam terkait dengan kegiatan penunjang dosen yang dilakukan.

- Tidak meratanya dalam pembagian tugas,

- Data penunjang tidak dapat dilacak dengan mudah ketika dibutuhkan, dan

- Data penunjang tidak terintegrasi dan terstruktur dengan baik.

Dibutuhkan sebuah rancangan proses bisnis usulan, rancangan dokumen blueprint, dan rancangan user interface yang sesuai dengan mekanisme kinerja bidang penunjang berdasarkan Tel-U Point di Fakultas Rekayasa Industri Universitas Telkom dengan visualisasi yang menarik dan dapat diakses dimanapun. Dengan rancangan sistem informasi mekanisme kinerja bidang penunjang berbasis website ini maka diharapkan pemegang kontrol dalam setiap prosesnya dapat tergambar dengan jelas, data penunjang dapat terintegrasi dengan baik, dan dari pengisian dan penyimpanan data dapat terotomatisasi didalam sistem.

\section{TINJAUAN PUSTAKA}

Kajian Terdahulu

Referensi [3] melakukan penelitian tentang "Rancang Bangun Website Toko Online Menggunakan Metode Waterfall". Dalam penelitian tersebut menghasilkan sebuah website yang dapat menjadi media promosi dan memperluas jangkauan pemasaran produk, agar konsumen di daerah Bengkalis dapat dengan mudah mengakses setiap produk yang diperlukan dengan cepat tanpa harus mengunjungi toko secara langsung untuk membeli barang atau produk.

Referensi [4] melakukan penelitian tentang "Web Based Advertising Information System Design For Newspaper". Dalam penelitian tersebut menghasilkan sebuah website E-Commerce yang dapat memudahkan pelanggan dalam mempromosikan produk mereka dan memberikan fasilitas untuk booking iklan di Koran Harian Singgalang. Karyawan juga diberikan kemudahan dalam mengelola data pemesanan dan pembayaran untuk iklan online.

Referensi [5] melakukan penelitian tentang "Perancangan Aplikasi Sistem Penilaian Kinerja Karyawan Dengan Metode MBO dan BARS (Studi Kasus PLTA Maninjau". Dalam penelitian tersebut menghasilkan sebuah rancangan aplikasi penilaian performansi pada PLTA Maninjau menggunakan metode BARS dan MBO, untuk menjawab semakin meningkatnya kebutuhan penyediaan data yang cepat. Pembuatan aplikasi dilakukan menggunakan Microsoft Excel.

Referensi [6] melakukan penelitian tentang "Penilaian Performansi Kerja Account Manager dengan Menggunakan Metode MBO (Management By Objectives) dan RICH (Rank Inclusion In Criteria Hierarchies)". Dalam penelitian tersebut menghasilkan sistem yang dapat melakukan pemrosesan dengan benar dan sesuai dengan metode yang diterapkan. Sistem ini dapat melakukan perangkingan pada nilai bobot yang sama. Sistem ini dimungkinkan menjadi fleksibel, dimana program dan sub program yang diberikan bisa bertambah atau berkurang sesuai dengan perubahan situasi dan kondisi.

Referensi [7] melakukan penelitian tentang "Rancang Bangun Sistem Informasi Penilaian Kinerja Karyawan Pada CV. Lightmint Contractor Dengan Metode Management By Objective". Dalam penelitian tersebut menghasilkan website sistem informasi penilaian kinerja karyawan yang bisa meminimalkan waktu dalam menilai setiap karyawan, dan mendapatkan laporan yang diharapkan oleh pemimpin yang akurat, serta karyawan juga dapat melihat apakah mereka sudah mempunyai nilai yang diharapkan sehingga dapat membantu perusahaan untuk memonitoring kinerja dari para karyawan untuk memenuhi standarisasi nilai yang diharapkan oleh perusahaan.

Adapun penelitian diatas yang mendekati dengan penelitian penulis yaitu referensi [7] yang menghasilkan website sistem informasi untuk penilaian kinerja. Perbedaan penelitian penulis dengan penelitian diatas adalah dalam perancangan sistem penulis menggunakan metode waterfall model dengan lingkup keilmuan Management By Objectives. Sedangkan persamaanya adalah dimana penelitian di atas dengan penulis yaitu sama-sama menggunakan bahasa pemograman PHP dan database MySQL.

Landasan Teori

Blueprint

Cetak biru adalah rincian dinamis untuk arsitektur-arsitektur yang memanfaatkan proses dan kerangka yang terstruktur. Cetak biru tersebut mengandung rincian bisnis, informasi dan teknologi saat ini dan yang diusulkan perusahaan untuk masa depan [8].

Analisis Gap \& Fit

Analisis Gap \& Fit adalah sebuah metodologi untuk membandingkan dan mengevaluasi sebuah proses bisnis dalam perusahaan untuk menemukan sebuah ketidaksesuaian (gap) dan kesesuaian ( $f i t$ ) [9]. Dua kemampuan utama sangat penting untuk melaksanakan analisis gap-fit yang efektif:

- Pemahaman rinci tentang karakteristik dan komponen tertentu dari organisasi target.

- Pemahaman rinci tentang kemampuan produk perangkat lunak yang merupakan kandidat untuk implementasi.

Singkatnya, perbandingan harus dibuat. Perangkat lunak standar baik 'cocok' dengan organisasi target, atau tidak. Jika 'cocok', maka produk dapat dipilih untuk implementasi. Jika tidak 'pas', maka keputusan harus diambil. Produk perangkat lunak dapat dimodifikasi (mis. Ditingkatkan) untuk mengisi celah (tidak 
disarankan), atau produk tersebut dapat ditolak atau produk yang memberikan kesesuaian yang lebih baik [9].

Cycle Time

Cycle Time atau waktu siklus adalah "Waktu aktual yang diambil untuk mengubah input menjadi output" [10]. Terdapat tiga kategori dalam cycle time, yaitu:

- $\quad$ RVA (Real Value Added): mencakup proses penting yang mengubah input menjadi output yang diperlukan untuk memenuhi kebutuhan pelanggan dan nilai tersebut telah dirasakan oleh pelanggan. Contoh: Product development, Material procurement, Design, Fabrication, Assembly, Finishing, Packaging, After sales service [10].

- $\quad$ BVA (Business Value Added): aktivitas-aktivitas dari suatu proses yang tidak memberikan nilai tambah bagi output proses secara langsung, tetapi aktivitas ini diperlukan dalam proses bisnis sebagai pendukung. Contoh: Scheduling, Marketing, Career planning, Auditing [10].

- $\quad$ NVA (Non Value Added): aktivitas dari suatu proses yang tidak memberikan nilai tambah kepada customer maupun dalam proses bisnis. Contoh: Redundant inspections, Filling in forms, Rework, Excessive transit, Waiting, Storage [10]. RACI Matriks

Diagram RACI digunakan untuk menggambarkan peran dan tanggung jawab tim atau individu dalam menyampaikan proyek

[11]. RACI adalah istilah yang mengacu pada:

- Responsible: Orang tersebut ditugaskan untuk menyelesaikan pekerjaan. Dapat mendelegasikan pekerjaan atau mungkin didukung oleh orang lain. Hanya satu orang yang bertanggung jawab, pikirkan pemimpin atau manajer [11].

- Accountable: Orang yang akan keluar dari paket / hasil kerja. Pada akhirnya, hanya satu orang, tetapi sering termasuk orang lain (mis. Dokumen penandatanganan yang membutuhkan tanda tangan dari beberapa pemberi persetujuan) [11].

- Consulted: Orang-orang yang berkontribusi pada pekerjaan dengan memberikan informasi (konsultasi), baik dengan memberikan informasi atau langsung bekerja sesuai arahan orang yang bertanggung jawab [11].

- Inform: Orang-orang yang perlu Diinformasikan, tetapi tidak berkontribusi (mis. Tidak memiliki peran aktif) [11].

Waterfall Model

Waterfall model, kadang-kadang disebut siklus hidup klasik, menyarankan pendekatan sistematis dan berurutan untuk pengembangan perangkat lunak yang dimulai dengan spesifikasi kebutuhan pelanggan dan berkembang melalui perencanaan, pemodelan, konstruksi, dan penyebaran, yang berpuncak pada dukungan berkelanjutan dari perangkat lunak yang telah selesai. Berikut merupakan fase-fase dalam model waterfall menurut referensi Pressman [12].

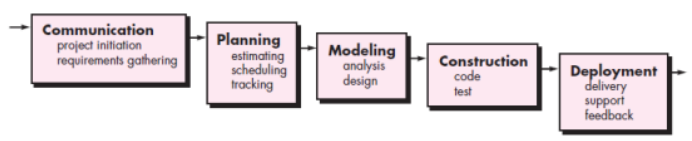

Gambar 2. Waterfall Model

Sumber: Roger S. Pressman, 2010

Analisa dan Perancangan Sistem

Analisa dan Perancangan Sistem dipergunakan untuk "menganalisis, merancang dan mengimplementasikan peningkatan-peningkatan fungsi bisnis yang dapat dicapai melalui penggunaan sistem informasi terkomputerisasi" [12]. Berikut merupakan perancangan sistem yang digunakan.

- $\quad$ Entity Relationship Diagram (ERD)

Entity Relationship Diagram (ERD) adalah gambaran pada sistem dimana di dalamnya terdapat hubungan antara entitas beserta relasinya [12].

\section{- Data Flow Diagram (DFD)}

DFD berfungsi untuk menggambarkan proses aliran data yang terjadi didalam sistem dari tingkat yang tertinggi sampai yang terendah, yang memungkinkan untuk melakukan dekomposisi, mempartisi atau membagi sistem kedalam bagian-bagian yang lebih kecil dan yang lebih sederhana [12].

- Use Case Diagram

Use case diagram menggambarkan fungsionalitas yang diharapkan dari sebuah sistem. Yang ditekankan adalah "apa" yang diperbuat sistem, dan bukan "bagaimana". Sebuah use case merepresentasikan sebuah interaksi antara aktor dengan sistem [13].

- Class Diagram

Class adalah sebuah spesifikasi yang jika diinstansiasi akan menghasilkan sebuah objek dan merupakan inti dari pengembangan dan desain berorientasi objek. Class menggambarkan keadaan (atribut/properti) suatu sistem, sekaligus menawarkan layanan untuk memanipulasi keadaan tersebut (metoda/fungsi) [13].

- Activity Diagram

Activity diagrams menggambarkan berbagai alir aktivitas dalam sistem yang sedang dirancang, bagaimana masingmasing alir berawal, decision yang mungkin terjadi, dan bagaimana mereka berakhir [13].

- Contex Diagram

Contex Diagram yang mewakili semua entitas eksternal yang dapat berinteraksi dengan sistem, baik secara langsung maupun tidak langsung. Diagram semacam itu menggambarkan sistem di pusat, tanpa detail struktur interiornya, dikelilingi oleh semua sistem, lingkungan, dan aktivitas interaksinya [12].

\section{- Physical Data Model}

Physical Data Model (PDM) adalah model yang menggunakan sejumlah tabel untuk menggambarkan data serta hubungan antara data-data tersebut [14].

\section{Model Konseptual}

Model konseptual merupakan kerangka model dari rancangan terstruktur yang menjelaskan variabel-variabel yang digunakan dalam penelitian serta hubungan keterkaitan antar variabel tersebut, dimana model konseptual dapat menentukan penataan masalah sehingga dapat dengan jelas mengetahui letak permasalahan dari penelitian. Berikut ini merupakan model konseptual pada mekanisme kinerja bidang penunjang dosen Universitas Telkom: 




Gambar 3. Model Konseptual

\section{HASIL DAN PEMBAHASAN}

\section{Communication}

Identifikasi Masalah

Permasalahan yang terjadi pada sistem mekanisme kinerja bidang penunjang dosen di Fakultas Rekayasa Industri Universitas Telkom diantaranya:

- Untuk pengisian data penunjang masih dilakukan secara manual karena hanya berupa rubrik excel, dan

Di dalam rubrik excel tersebut terdapat pilihan seperti surat tugas "ada" atau "tidak ada" dan laporan "ada" atau "tidak ada”.

- Tidak ada fasilitas untuk menyimpan berkas penunjang karena tidak adanya sistem yang khusus mengatur dalam hal penunjang dosen. Evidence fisik (hardcopy/softcopy) dikelola secara manual oleh SDM Fakultas sehingga tidak terotomatisasi didalam sistem.

Analisis Sistem

- Pengambilan data dilakukan dengan cara manual beresiko terhadap ke-valid-an data yang masih rendah, disamping itu juga efisiensi waktu dan tenaga juga tidak maksimal.

- Data yang dipublikasikan hanya berupa rubrik excel menyebabkan informasi yang disampaikan kurang menarik dan membosankan.

\section{Planning}

\section{Kebutuhan Data}

Sumber Data

Sumber data yang digunakan dalam penulisan laporan ini adalah data sekunder. Data sekunder adalah data penelitian yang berupa tulisan, file atau informasi yang terlihat. Data yang dibutuhkan dalam desain sistem mekanisme kinerja bidang penunjang dosen ini diantaranya: daftar kategori penunjang dosen, bobot SKS per item kategori penunjang, data dosen fakultas rekayasa industri, proses bisnis usulan.

Teknik Pengumpulan data.

- Metode Wawancara

Menanyakan bagaimana proses pengolahan data penunjang dan menanyakan tentang sistem yang sedang digunakan apakah dalam pengolahan data menggunakan sistem komputerisasi atau masih manual dalam penyimpanan data.

- Metode Studi Pustaka

Metode ini dilakukan dengan membaca dan memahami jurnal atau buku-buku literatur yang ada hubungannya dengan penelitian yang digunakan sebagai landasan teori dalam pemecahan masalah agar penulisan dan penelitian tidak menyimpang dari teori.

Modeling

Proses Bisnis Usulan dapat dilihat pada Gambar 4.



Gambar 4. Proses Bisnis Usulan

Context Diagram dapat dilihat pada Gambar 5.

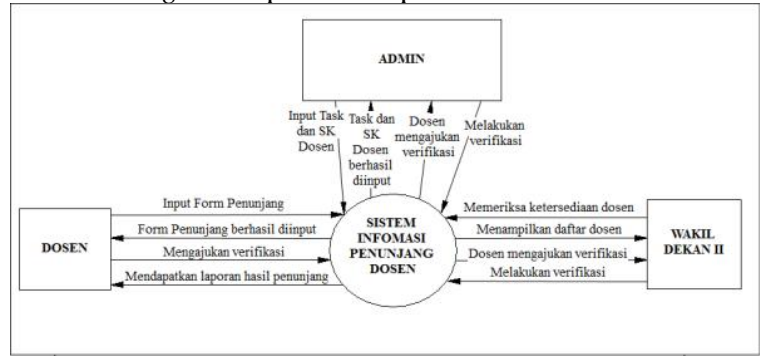

Gambar 5. Context Diagram

Use Case Diagram dapat dilihat pada Gambar 6.

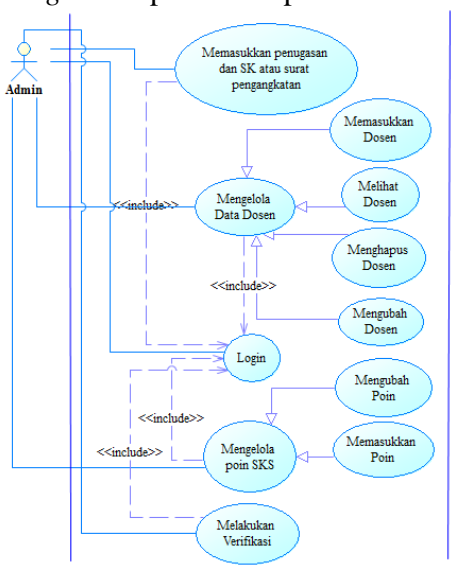

Gambar 6. Use Case Diagram Admin 


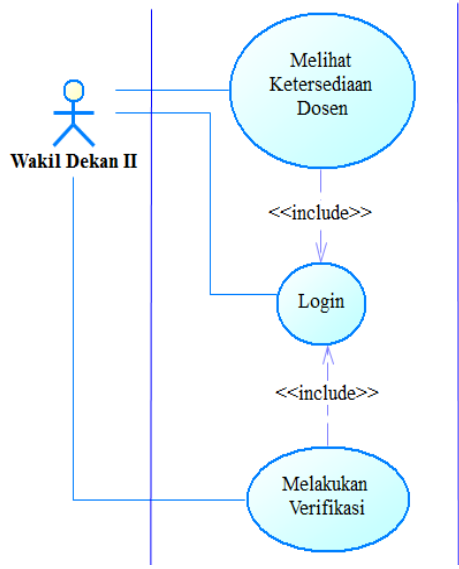

Gambar 7. Use Case Diagram Wakil Dekan II

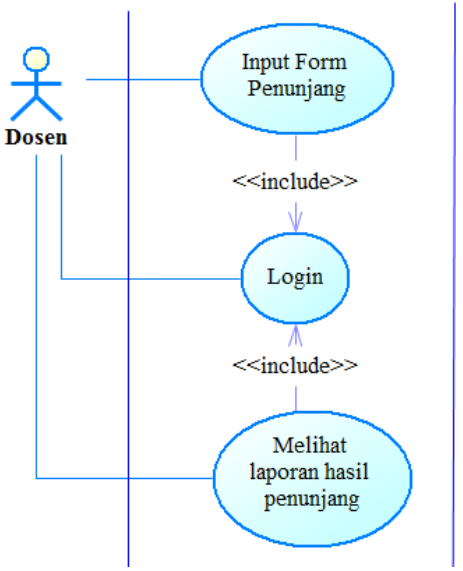

Gambar 8. Use Case Diagram Dosen

Entity Relationship Diagram (ERD) dapat dilihat pada Gambar 9.

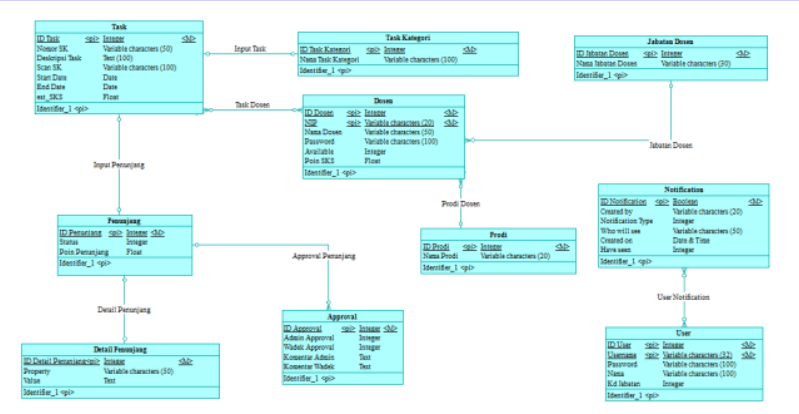

Gambar 9. Entity Relationship Diagram

\section{User Interface}

Pada penelitian ini menghasilkan sebuah website Penunjang Dosen. Website penunjang dosen ini berfungsi untuk memberikan kemudahan kepada dosen agar dapat mengetahui informasi mengenai penugasan beserta dengan poin SKS yang didapatkan dan dapat menyimpan berkas-berkas penugasan dengan mudah. Terdapat bagian admin yang dapat menginput task dan SK, mengelola data dosen, melakukan verifikasi, dan mengelola poin SKS. Terdapat bagian wakil dekan II yang dapat melihat ketersediaan dosen dan melakukan verifikasi. Terdapat bagian dosen yang dapat menginput form penunjang dan melihat laporan hasil penunjang. Berikut merupakan user interface dari user admin website penunjang dosen.

- Halaman Login

Halaman login untuk melakukan proses login user.

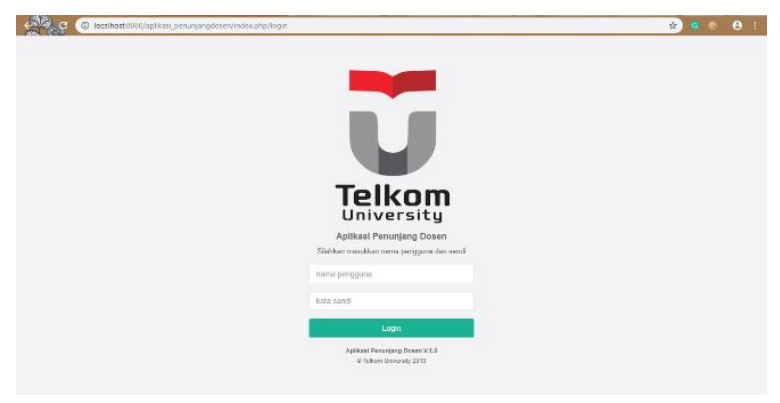

Gambar 10. Halaman Login

- Halaman Dashboard

Halaman dashboard merupakan tampilan awal dari website. Dashboard untuk user admin terdapat menu data person, data university, tasks, approval list, dan input poin SKS.

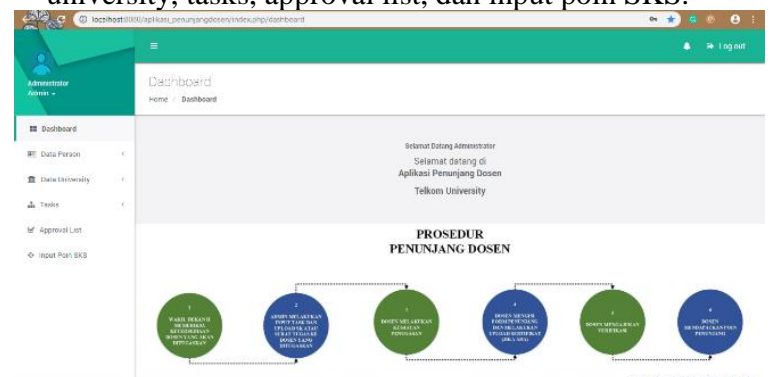

Gambar 11. Halaman Dashboard

- Halaman daftar dosen

Halaman daftar dosen merupakan halaman untuk melihat data dosen seperti nama dosen, NIP, jabatan, prodi, poin SKS, status.

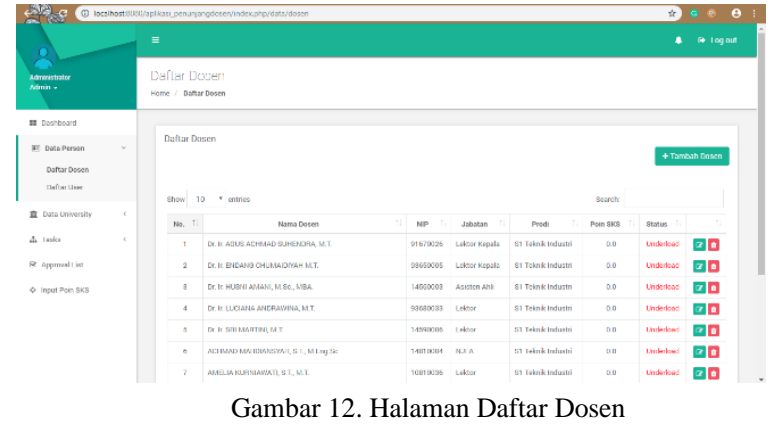

- Halaman daftar user

Halaman daftar user menampilkan nama user di dalam website penunjang dosen.

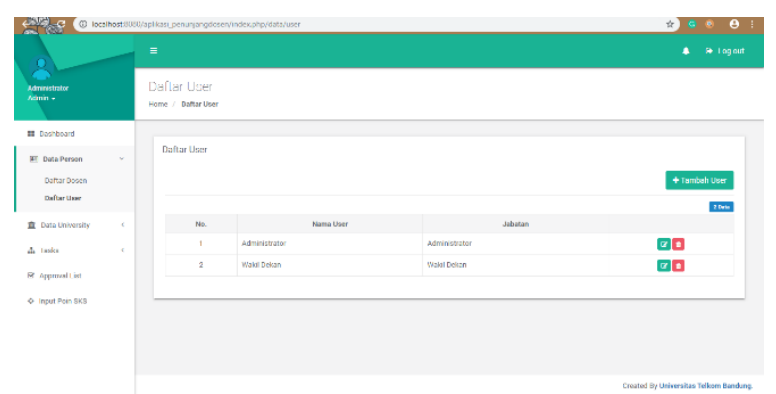

Gambar 13. Halaman Daftar User

- Halaman daftar prodi

Halaman daftar prodi menampilkan nama prodi di dalam website penunjang dosen. 


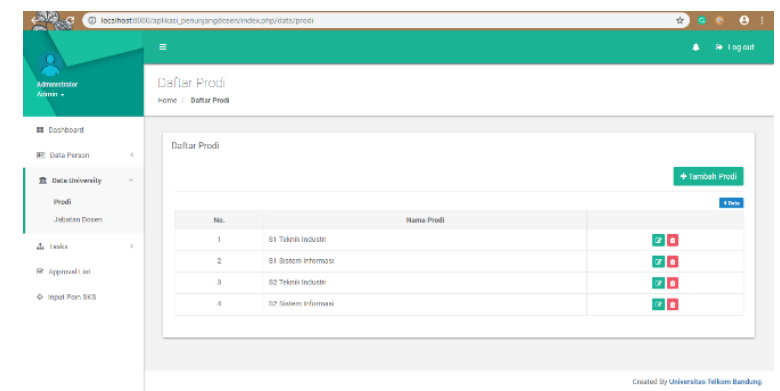

Gambar 14. Halaman Daftar Prodi

- Halaman jabatan dosen

Halaman jabatan dosen menampilkan nama jabatan dosen di dalam website penunjang dosen.

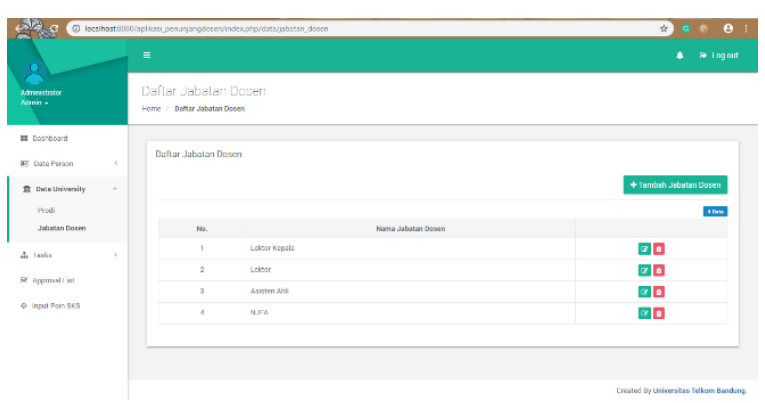

Gambar 15. Halaman Jabatan Dosen

- Halaman daftar task kategori

Halaman daftar task kategori menampilkan nama task kategori di dalam website penunjang dosen.



Gambar 16. Halaman Daftar Task Kategori

- Halaman input task dan SK

Halaman input task dan SK menampilkan nomor SK, tanggal penugasan, task kategori, unggah scan SK, deskripsi tugas, dan point estimation.



Gambar 17. Halaman Input Task dan SK

- Halaman daftar task

Halaman daftar task menampilkan nomor SK, tanggal penugasan, kategori, PIC, status, dan point estimation.

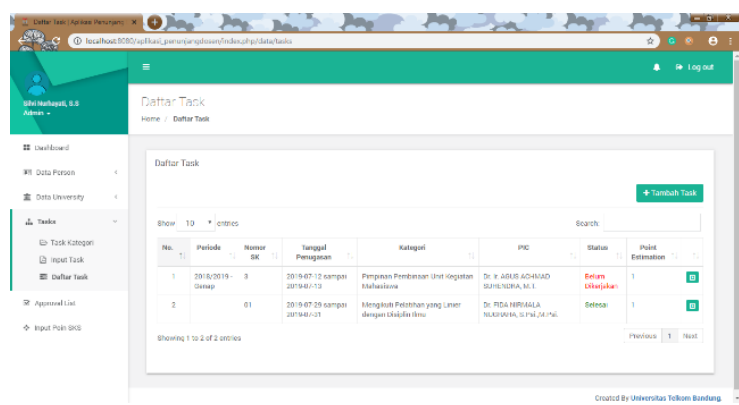

Gambar 18. Halaman Daftar Task

- Halaman waiting approval

Halaman waiting approval menampilkan nomor SK, tanggal penugasan, kategori, PIC, dan status.

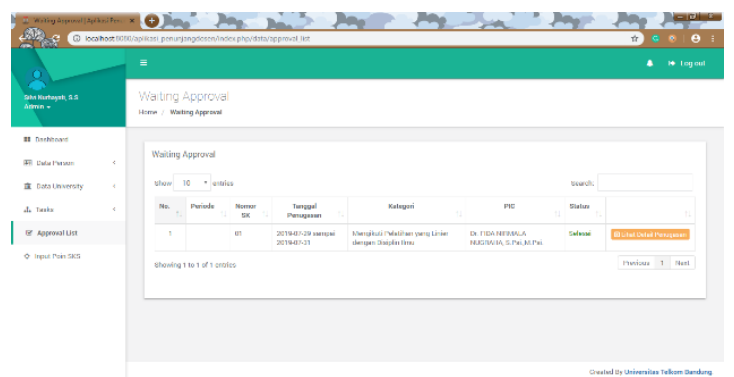

Gambar 19. Halaman Waiting Approval

- Halaman approved list

Halaman approved list menampilkan nomor SK, tanggal penugasan, kategori, PIC, admin approval, wadek approval, dan poin SKS.

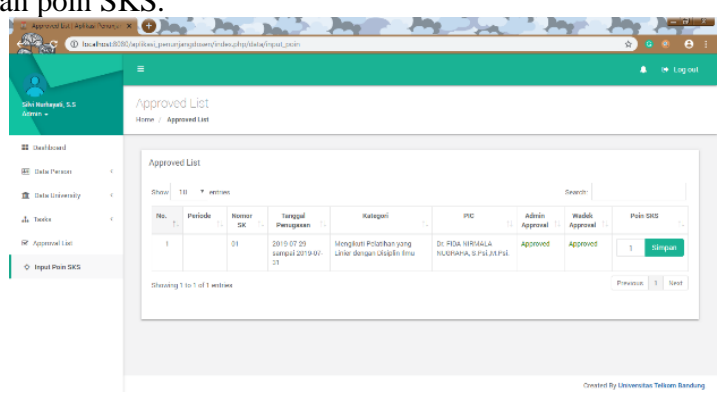

Construction

Gambar 20. Halaman Approved List

Construction merupakan proses membuat kode. Pembuatan program harus sesuai dengan perancangan dan desain yang telah dibuat sebelumnya. Dalam penelitian ini, rancangan hasil penelitian adalah membangun aplikasi dengan dua platform, yakni website dan mobile, oleh karena itu sebaiknya penulisan program dilakukan menggunakan bahasa pemrograman PHP dengan framework CodeIgniter dan basis data My SQL untuk platform website dan Ionic Framework, SQLite untuk platform mobile.

Dalam penelitian ini rancangan pengujian sistem dilakukan dengan melakukan pengujian black-box terhadap semua fungsi dalam aplikasi. Pengujian black-box merupakan salah satu pengujian aplikasi atau perangkat lunak yang berfokus pada persyaratan fungsional perangkat lunak. Karena itu uji coba black-box memungkinkan pengembang software untuk membuat himpunan kondisi input yang akan melatih seluruh syarat-syarat fungsional suatu program. 
Tabel 1. Hasil User Acceptance Test

\begin{tabular}{|c|c|c|c|}
\hline No & User & Hasil & \multicolumn{1}{c|}{ Keterangan } \\
\hline 1 & $\begin{array}{l}\text { Admin } \\
\text { (Kaur } \\
\text { SDM } \\
\text { Fakultas) }\end{array}$ & Berhasil & $\begin{array}{l}\text { Aplikasi dapat dijalankan sesuai } \\
\text { dengan yang di harapkan }\end{array}$ \\
\hline 2 & $\begin{array}{l}\text { Wakil } \\
\text { Dekan II }\end{array}$ & Berhasil & $\begin{array}{l}\text { Aplikasi dapat dijalankan sesuai } \\
\text { dengan yang di harapkan }\end{array}$ \\
\hline 3 & Dosen & Berhasil & $\begin{array}{l}\text { Aplikasi dapat dijalankan sesuai } \\
\text { dengan yang di harapkan }\end{array}$ \\
\hline
\end{tabular}

\section{KESIMPULAN}

Berdasarkan penelitian yang telah dilakukan, maka dapat diambil kesimpulan sebagai berikut:

1. Rancangan proses bisnis usulan yang diberikan dapat meminimalisir adanya ketidakadilan dalam proses verifikasi dan pembagian poin SKS, sehingga sesuai dengan mekanisme kinerja bidang penunjang berdasarkan Tel-U Point di Fakultas Rekayasa Industri Universitas Telkom.

2. Rancangan dokumen blueprint dikembangkan menggunakan metode Waterfall model agar pemegang kontrol dalam setiap prosesnya dapat tergambar dengan jelas, sehingga sesuai untuk mekanisme kinerja bidang penunjang berdasarkan Tel-U Point di Fakultas Rekayasa Industri Universitas Telkom.

3. Rancangan user interface Sistem informasi website penunjang dosen terdapat halaman login, dashboard, halaman daftar dosen, daftar user, daftar prodi, jabatan dosen, daftar task kategori, input task dan SK, daftar task, waiting approval dan approval list, sehingga data penunjang dapat terintegrasi dengan baik dan dari pengisian dan penyimpanan data dapat terotomatisasi didalam sistem.

\section{REFERENCES}

[1] UU Nomor 2, Undang-Undang Republik Indonesia. 1989, pp. 1-27.

[2] Kementerian Riset dan Pendidikan Tinggi, Puspawarna Pendidikan Tinggi Indonesia. 2016.

[3] M. Susilo, R. Kurniati, and Kasmawi, "RANCANG BANGUN WEBSITE TOKO ONLINE MENGGUNAKAN METODE WATERFALL," vol. 2, no. 2, pp. 98-105, 2018.

[4] T. Sriwahyuni, A. Huda, D. S. Afka, and D. Suadi, "WEB BASED ADVERTISING INFORMATION SYSTEM DESIGN FOR NEWSPAPER," Technology, vol. 23, pp. 27-33, 2015.

[5] Taufik, P. Fithri, and Y. E. Prathama, "Perancangan Aplikasi Sistem Penilaian Kinerja Karyawan Dengan Metode MBO dan BARS (Studi Kasus PLTA Maninjau)," vol. 13, no. 2, pp. 760-770, 2014.

[6] A. Rifazka, D. Darmantoro, E. B. Setiawan, and S. Si, "PENILAIAN PERFORMANSI KERJA ACCOUNT MANAGER DENGAN MENGGUNAKAN METODE MBO ( MANAGEMENT BY OBJECTIVE ) DAN RICH ( RANK INCLUSION IN CRITERIA HIERARCHIES )," vol. 2009, no. Snati, pp. 101-107, 2009.

[7] M. H. Abdillah, "RANCANG BANGUN SISTEM INFORMASI PENILAIAN KINERJA KARYAWAN PADA CV. LIGHTMINT CONTRACTOR DENGAN METODE MANAGEMENT BY OBJECTIVE," STIKOM Surabaya, Surabaya, 2013.

[8] W. Syahindra, "PERANCANGAN CETAK BIRU TEKNOLOGI INFORMASI MENGGUNAKAN PERANCANGAN CETAK BIRU TEKNOLOGI
INFORMASI MENGGUNAKAN ENTERPRISE ARCHITECTURE PLANNING," J. Inform. Sains dan Teknol., vol. 3, no. October, 2018.

[9] Y. Muchsam, Falahah, and G. I. Saputro, "PENERAPAN GAP ANALYSIS PADA PENGEMBANGAN SISTEM PENDUKUNG," Semin. Nas. Apl. Teknol. Inf. 2011, no. Snati, pp. 17-18, 2011.

[10] P. Griesberger, S. Leist, and G. Zellner, "ANALYSIS OF TECHNIQUES FOR BUSINESS PROCESS IMPROVEMENT," 2010.

[11] B. M. L. Smith and J. Erwin, "Role \& Responsibility Charting ( RACI )," 2015.

[12] R. S. Pressman, Software Engineering, Seventh Ed. Mc Graw-Hill, 2010.

[13] J. Rumbaugh, I. Jacobson, and G. Booch, The Unified Modeling Language Reference Manual, 4th ed. Reading, Massachusetts: Addison Wsley Longman, Inc, 2017.

[14] R. H. Kusuma, "Sistem Penunjang Keputusan Menggunakan Metode Topsis guna Menentukan Poli Rawat Jalan di Kota Malang Berbasis Webgis," J. Inf. Technol., vol. 03, no. January, pp. 67-73, 2015. 